\title{
Validation of a surgical invasiveness index in patients with lumbar spinal disorders registered in the Spine Tango registry
}

\author{
Erik M. Holzer ${ }^{1}$ (1) - Emin Aghayev ${ }^{1} \cdot$ Dave O'Riordan $^{1} \cdot$ Tamas F. Fekete $^{1} \cdot$ Dezső J. Jeszenszky $^{1} \cdot$ Daniel Haschtmann $^{1}$. \\ Francois Porchet ${ }^{1} \cdot$ Frank S. Kleinstueck ${ }^{1} \cdot$ Tim Pigott $^{2} \cdot$ Everard Munting $^{3} \cdot$ Andrea Luca $^{4} \cdot$ Anne F. Mannion $^{5}$
}

Received: 4 June 2020 / Revised: 26 September 2020 / Accepted: 21 October 2020 / Published online: 24 November 2020

(c) The Author(s) 2020

\begin{abstract}
Introduction Being able to quantify the invasiveness of a surgical procedure is important to weigh up its associated risks, since invasiveness governs the blood loss, operative time and likelihood of complications. Mirza et al. (Spine (Phila Pa 1976) 33:2651-2661,2008) published an invasiveness index for spinal surgery. We evaluated the validity of a modified version of the Mirza invasiveness index (mMII), adapted for use with registry data.

Methods A cross-sectional analysis was performed with data acquired from the Spine Tango registry including 21,634 patients. The mMII was calculated as the sum of six possible interventions on each vertebral level: decompression, fusion and stabilization either on anterior or posterior structures. The association between the mMII and blood loss, operative time and complications was evaluated using multiple regression, adjusting for possible confounders.

Results The mean $( \pm \mathrm{SD}) \mathrm{mMII}$ was $3.9 \pm 5.0$ (range 0-40). A 1-point increase in the mMII was associated with an additional blood loss of $12.8 \%$ (95\% CI 12.6-13.0; $p<0.001$ ) and an increase of operative time of $10.4 \mathrm{~min}$ (95\% CI 10.20-10.53; $p<0.001)$. The $R^{2}$ for the blood loss model was of $43 \%$ and for operative time, $47 \%$. The mean mMII was significantly $(p<0.001)$ higher in patients with surgical complications $(4.5 \pm 5.6)$ and general medical complications $(6.5 \pm 7.0)$ compared to those without (3.8 \pm 4.9$)$. Our results were comparable to those reported in the original publication of Mirza et al.

Conclusion The mMII appeared to be a valid measure of surgical invasiveness in our study population. It can be used in predictor models and to adjust for surgical case-mix when comparing outcomes in different studies or different hospitals/ surgeons in a registry.
\end{abstract}

Keywords Surgical invasiveness index $\cdot$ Lumbar spinal disorders $\cdot$ Validation $\cdot$ Spine Tango $\cdot$ Blood loss $\cdot$ Operative time $\cdot$ Complications

\section{Introduction}

Spine surgery involves a wide range of techniques and procedures with varying degrees of complexity when compared with, for example, hip or knee arthroplasty, where the procedures are more standardized and can be compared more

Erik M. Holzer

erik.holzer@bluemail.ch

Spine Center, Schulthess Klinik, Zurich, Switzerland

2 The Walton Centre Foundation Trust, Liverpool, UK

3 Clinique Saint Pierre, Ottignies, Belgium

4 IRCCS Galeazzi, Milan, Italy

5 Dept Teaching, Research and Development, Spine Center Division, Schulthess Klinik, Zurich, Switzerland easily [1]. There are large international and regional variations in the treatment of lumbar spinal disorders regarding the indications for surgery and extent of surgical procedures used $[2,3]$.

The "invasiveness" (magnitude and complexity) of a spinal surgical procedure has a significant influence on other characteristics of the operation [4]. For example, it has been shown that in patients undergoing lumbar decompression and arthrodesis, there is a significant increase in blood loss with an increasing number of segments operated on $[5,6]$. Intraoperative blood loss has been shown to be the most significant risk factor for early perioperative complications [7]. The degree of technical difficulty, the number of segments operated on and the use of different approaches not only influence blood loss, but also the duration of the operation. Nuttall et al. [6] showed an increase of operative time per 
level fused of $114 \pm 75 \mathrm{~min}$. Rates for surgical site infections and complications in general are significantly higher with increased operative time $[8,9]$.

As the aforementioned studies show, there is a significant correlation between the invasiveness of spinal procedures and the surgical outcome of an operation (i.e. blood loss, operative time and complication rate). Being able to quantify the invasiveness of an operation and its possible risks in terms of complications is important in the decision-making process for patients and surgeons. Having a valid and applicable index is also valuable for comparing outcomes and complication rates across studies and in benchmarking activities, such as those typically carried out in registries $[10,11,12]$.

Mirza et al. [4] developed and validated an invasiveness index for spinal surgery which was published in 2008 . The method counts a maximum of six possible interventions (anterior decompression, anterior fusion, anterior instrumentation, posterior decompression, posterior fusion, posterior instrumentation) on each vertebral level, and the invasiveness index is given by the sum of all interventions on all addressed levels. The authors evaluated the association between the index score and blood loss and operating time in 1723 cases. They found an increase in blood loss of additional $11.5 \%$ (calculated by natural log transformation) and an increase of operating time of $12.8 \mathrm{~min}$ for each unit increase in the index.

To the best of our knowledge, the index has not been validated in any other datasets. A large international spine registry, such as the Spine Tango registry of EUROSPINE, is ideal for evaluating the validity of such an invasiveness index. It is a registry with detailed information regarding the clinical history, pathology, surgical measures, surgical outcomes and adverse events/complications during the hospital stay. The data are recorded in a systematic fashion, using standardized forms, by the operating surgeons.

The aim of this study is to evaluate the validity of a modified version of the Mirza invasiveness index (mMII) using surgical data from the international Spine Tango registry.

\section{Methods}

\section{Patients}

The study data were extracted from the Spine Tango registry of EUROSPINE [13]. This international registry contains patient and physician-based data, collected prospectively, from 53 clinics in 17 countries. The main contributing countries (with more than 1000 submitted cases each) were: the UK, Switzerland, Germany and Belgium. Ethics Committee approval was obtained for the use of the registry data for the study (BASEC-Nr. 2018-01033).
Figure 1 shows the flow of patients through the study forming the final study group. The registry was searched for Spine Tango version 2011 Surgery forms, which were officially in use from January 2012 to July $2017(n=57,045)$. All patients with surgery of the lumbar spine (Th12-S1) for degenerative disease were included $(n=38,400)$. Procedures with dynamic stabilization $(n=4412)$ were excluded, as they were in the original paper [4]. Forms with missing data for the essential predictor variables (see below) were also excluded $(n=10,907)$. If a patient had multiple surgery records, only the first record available was included and the remainder $(n=1436)$ were discarded. Forms with obviously false data, such as the number of operated segments being clearly too high for the short operative time documented, were excluded $(n=11)$. The total number of patients included was 21,634 .

\section{Spine Tango documentation forms}

The Spine Tango 2011 Surgery form, completed by the operating surgeon, contained detailed information about the surgery, documented using standardized fields.

To calculate the mMII (see later), data from the following Tango Surgery fields were used: anterior or posterior access; surgical measures (decompression, fusion, rigid stabilization); the specific surgical measures used (for example, discectomy, laminectomy, interbody fusion $\{$ TLIF $\}$, interbody stabilization with cage); and number of segments operated on. Table 1 shows the manner in which the specific procedures on the Spine Tango Surgery form were attributed to one of the six surgical components.

As dependent variables to be predicted by the mMII, data from the fields operative time in hours (categories of $<1,1-2,3-4,4-5,5-6,6-8,8-10,>10 \mathrm{~h})$ and blood loss in millilitres (categories of $<100,100-500$, $500-1000,1000-2000,>2000 \mathrm{ml}$ ) were used. Operative time and blood loss were selected as dependent variables, because they are easily obtainable for every operation and were expected to be closely linked to the procedure and its invasiveness [6-9]. Intraoperative and postoperative complications (grouped as either surgical or general medical) were additional dependent variables to be predicted. The following surgical complications were documented on the Tango Surgery form as either present or absent: nerve root damage, spinal cord damage, dural tear, vascular injury, fracture of vertebral structures, epidural hematoma, other hematoma, radiculopathy, CSF leak, motor dysfunction, sensory dysfunction, bowel/bladder dysfunction, wound infection, implant malposition, implant failure, wrong level, other surgical complication. Dural tear, the most common surgical complication, was also investigated separately. The following general medical complications were similarly documented as present 
Fig. 1 Selection of the study population

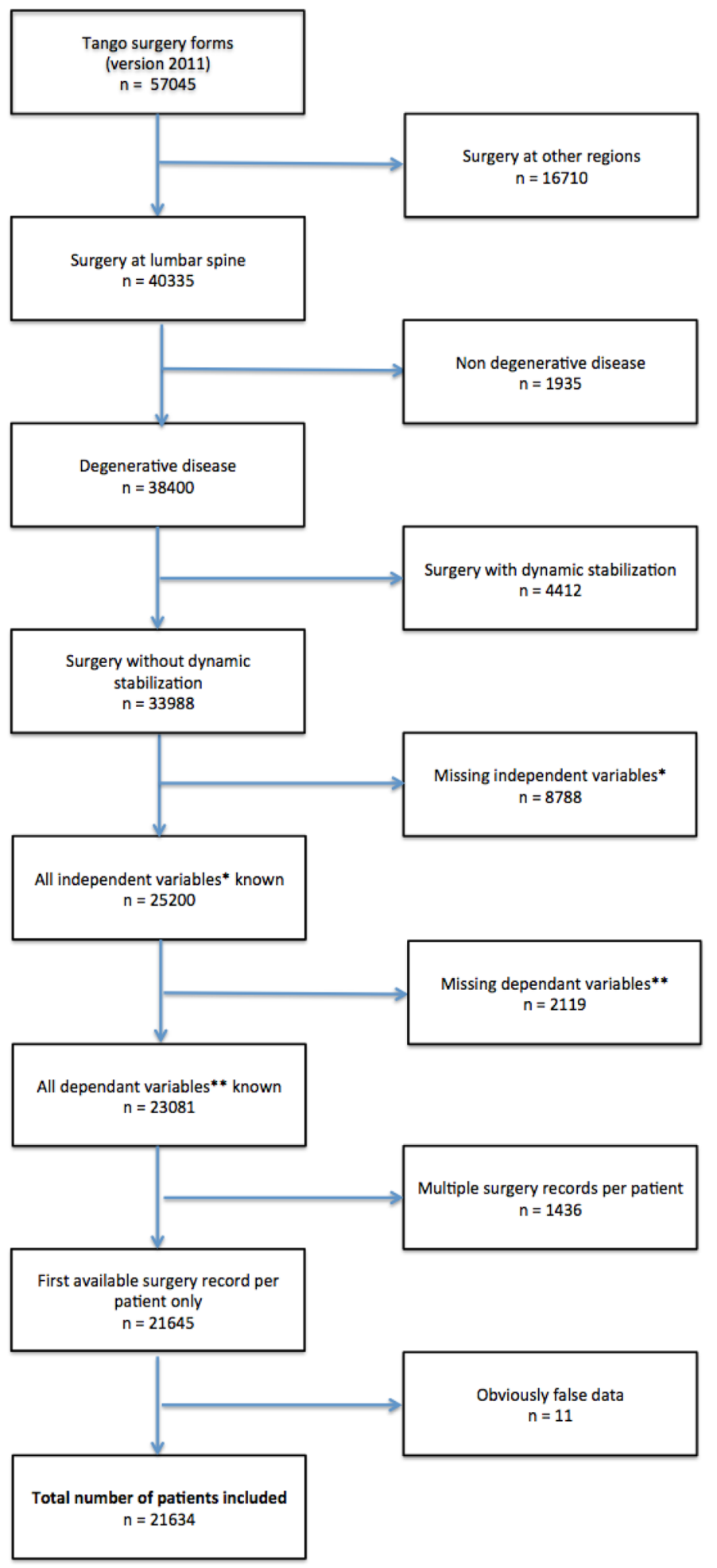

* Independent variables (body mass index, gender, age, number of previous spine sugeries, ASA score) ** Dependent variables (blood loss, opertive time) 
Table 1 Summary showing how the specific procedures listed on the Spine Tango Surgery form were attributed to the six surgical components defined by Mirza et al. [1]

Anterior decompression: the number of vertebrae requiring partial or complete excision of the vertebral body (regardless of surgical approach or location of skin incision), or the disc caudal to that vertebra if the disc is excised from an anterior approach

- Discectomy (if ant. access checked)

- Vertebrectomy (partial or full)

- Osteotomy (if ant. decompression checked)

- Sequestrectomy (if ant. access checked)

- Uncoforaminotomy*

- Other decompression (if ant. decomp. checked)
Posterior decompression: the number of vertebrae requiring laminectomy or foraminotomy at the foramens caudal to their pedicles, and/or discectomy at the disc caudal to the vertebral body if the disc is excised from a posterior approach

- Osteotomy (if post. decompression checked)

- Laminotomy

- Hemi-laminectomy

- Laminectomy

- Facet joint (partial or full)

- Flavectomy

- Flavotomy

- Foraminotomy

- Laminoplasty

- Other decompression (if post. decomp. checked)

- Discectomy (if post. access checked)

- Sequestrectomy (if post. access checked)

Posterior fusion: the number of vertebrae that have graft material on their lamina, facets, or transverse processes

- PLIF

- TLIF

- XLIF

- Posterolateral fusion

- Posterior fusion

- Other fusion (if post. fusion checked)

Posterior stabilization: the number of vertebrae that have screws, hooks or wires attached to their pedicles, facets, lamina or transverse processes

- Pedicle screws with rod

- Facet screws

- Transarticular screw*

- Laminar hooks with rod

- Pedicle hooks with rod

- Lateral mass screw with rod*

- Laminar screws*

- Other rigid stabilization (if post. rigid stab. checked)

*not included in this study, as only pertaining to cervical spine

or absent: anaesthesiological, cardiovascular, pulmonary, thromboembolism, death, cerebral, kidney/urinary, liver/ GI, other general medical complication.

Data on potential confounders were also extracted from the Tango Surgery form to be used as control variables in the statistical models (see below). These included: age, gender, body mass index (BMI; categories of $<20,20-25$, $26-30,31-35,>35 \mathrm{~kg} / \mathrm{m}^{2}$ ), comorbidity (American Society of Anaesthesiologists Physical Status Score; ASA categories 1-5) and number of previous spine surgeries (categories of $0,1,2,3,4,5,>5$ ).

\section{Calculation of the mMII}

The original formula used by Mirza et al. [4] to calculate the invasiveness index was as follows:

"A value of 1 unit was given for each surgical component performed at each vertebra: anterior decompression, anterior fusion, anterior instrumentation, posterior decompression, posterior fusion, posterior instrumentation. The score for each surgical component indicated the total number of vertebrae at which 
that procedural element was performed. The index was defined as the sum of the six surgical component scores. Spinal procedures that did not involve decompression, fusion, or instrumentation, such as irrigation and debridement, were assigned an index value of $0 . "$

Table 1 shows how the surgical procedures are defined.

The Spine Tango Surgery form (version 2011) does not specify what procedure was performed on how many segments. We therefore had to assume that the answer in the field "number of segments" applied to all documented procedures (decompression, fusion, stabilization) even though this was unlikely to be the case in all patients. Because of this difference, we refer to our index as a modified version of that proposed by Mirza et al. [4].

\section{Statistical analysis}

Descriptive data are presented as means \pm standard deviation (SD) or percentages of the respective patient group. Multiple regression analyses were performed to investigate the influence of the mMII (independent variable; see above) on firstly, operative time and secondly, blood loss (dependent variables) while controlling for possible confounders (independent variables). All variables were entered into the model simultaneously. Since the operative time is recorded on the Spine Tango form as a range (e.g. 1-2 h), for the statistical analysis, the mean of the range (e.g. $1.5 \mathrm{~h}$ for the category 1-2 h) was used, to allow the regression coefficients to be interpreted in real units of time. For operative time $>10 \mathrm{~h}$, we used the value $11 \mathrm{~h}$. The same was done for blood loss, also recorded as a range that was converted to the mean of the range (e.g. the category 100-500 millilitres resulted in the mean of 300 millilitres) for statistical analysis. For blood loss $>2000$ millilitres, we used the value 3000 millilitres.

A natural $\log$ transformation was used for the blood loss values, as was also done by Mirza et al. [4], because the distribution of values was skewed. The results of the multiple regression analyses are presented as regression coefficients $(B)$ with $95 \%$ confidence intervals $(95 \% \mathrm{CI})$ and corresponding $p$ values. The regression coefficients in the regression models with log-transformed variables can be interpreted as percentage change of the dependent variable with one unit change in one independent variable, while other independent variables are held constant (e.g. 1 unit increase in the $\mathrm{mMII}\{B=0.128\}$ leads to $12.8 \%$ increased blood loss when the other independent variables are constant). The regression coefficients for blood loss cannot be interpreted directly as change of blood loss in millilitres due to the log transformation.

Logistic regression models were built to investigate the association between the mMII and perioperative complications (surgical and general medical). The occurrence of complications was the dependent variable, and the mMII, patient age, number of previous spine surgeries, BMI, ASA score and gender were independent variables.

Statistical significance was accepted at $p<0.05$. Statistical analysis was carried out using SPSS version 25 (IBM Corp., USA, 2017).

\section{Results}

\section{Study population}

The baseline characteristics of the final study population consisting of 21,634 patients are shown in Table 2. Approximately one-third of the patients had a disc herniation, onethird spinal stenosis and the rest had other degenerative diseases (Table 2). The mean mMII for all patients was 3.9 (SD 5.0) with a range from 0 to 40 (Fig. 2).

\section{mMIl versus blood loss}

The mean blood loss was 207 (SD 307) $\mathrm{ml}$ with a range from 50 to $3000 \mathrm{ml}$, and the median blood loss was $50 \mathrm{ml}$. Table 2 shows the distribution of category answers for this variable. The multiple regression model showed a coefficient of determination $\left(R^{2}\right)$ of 0.43 , meaning $43 \%$ of the variance in blood loss was accounted for by the model. The mMII itself explained a significant $34 \%$ of the variance in blood loss. An increase of 1 point in the mMII was associated with an additional blood loss of $12.8 \%$ (95\% CI 12.6-13.0; $p<0.001$ ) (Table 3). Due to the log transformation of the blood loss values, the regression coefficients are interpreted as additional blood loss in percent change.

\section{mMIl versus operative time}

The mean operative time was 101 (SD 80) min with a range from 30 to $660 \mathrm{~min}$. Table 2 shows the distribution of category answers for operative time. The multiple regression model showed a $R^{2}$ of 0.47 , meaning $47 \%$ of the variance in operative time was accounted for by the model. The mMII uniquely explained a significant $38 \%$ of the variance in operative time. An increase of 1 point in the mMII was associated with an increase of operative time of $10.4 \mathrm{~min}(95 \% \mathrm{CI}$ $10.20-10.53 ; p<0.001$ ) (Table 4).

\section{mMII versus complications}

Perioperative surgical complications occurred in 2117 (9.8\%) and general medical complications in $563(2.6 \%)$ patients. Simultaneous surgical and general medical complications occurred in $138(0.6 \%)$ patients. Logistic regression models confirmed that the mMII was a predictor of 
Table 2 Study population with baseline characteristics
Number of patients

21,634

Age, yrs (mean $\pm \mathrm{SD})$

$57.5 \pm 16.1$

Gender (\% within patients)

Female

$10,777(49.8 \%)$

Male

$10,857(50.2 \%)$

BMI, $\mathrm{kg} / \mathrm{m}^{2}$

$<20$

$753(3.5 \%)$

20-25

$6647(30.7 \%)$

26-30

$8539(39.5 \%)$

$31-35$

$>35$

$4099(18.9 \%)$

$1596(7.4 \%)$

Morbidity

ASA I (no disturbance)

$7262(33.6 \%)$

ASA II (mild/moderate)

$11,051(51.1 \%)$

ASA III (severe)

$3226(14.9 \%)$

ASA IV (life threatening)

$95(0.4 \%)$

Main pathology

Lumbar disc herniation

$7125(32.9 \%)$

Lumbar spinal stenosis without spondylolisthesis

$7055(32.6 \%)$

Lumbar degenerative spondylolisthesis

$2554(11.8 \%)$

Lumbar degenerative segment disease

$797(3.7 \%)$

$710(3.3 \%)$

Lumbar degenerative deformity

$3393(15.7 \%)$

Number of levels operated on

$$
\begin{aligned}
& 1 \text { segment } \\
& 2 \text { segments } \\
& 3 \text { segments } \\
& 4 \text { segments } \\
& 5 \text { segments } \\
& >5 \text { segments }
\end{aligned}
$$

Number of previous spine surgeries

0

1

2

3

4

5

$>5$

$15,693(72.5 \%)$

$3953(18.3 \%)$

$1423(6.6 \%)$

$439(2.0 \%)$

$101(0.5 \%)$

$25(0.1 \%)$

$16,286(75.3 \%)$

$3831(17.7 \%)$

$1032(4.8 \%)$

$301(1.4 \%)$

$107(0.5 \%)$

$23(0.1 \%)$

$54(0.2 \%)$

Operating time, hrs

$<1$

$7272(33.6 \%)$

1-2

8411 (38.9\%)

2-3

3014 (13.9\%)

3-4

$1673(7.7 \%)$

$706(3.3 \%)$

$321(1.5 \%)$

5-6

$176(0.8 \%)$

$26(0.1 \%)$

8-10

$35(0.2 \%)$

Blood loss, ml

$<100$

$13,480(62.3 \%)$

$100-500$

$6178(28.6 \%)$

$500-1000$

$1497(6.9 \%)$ 
Table 2 (continued)

\begin{tabular}{ll}
\hline $1000-2000$ & $411(1.9 \%)$ \\
$>2000$ & $68(0.3 \%)$ \\
Surgical measures* & \\
Anterior decompression & $793(3.7 \%)$ \\
Posterior decompression & $20,567(95.1 \%)$ \\
Anterior fusion & $4978(23.0 \%)$ \\
Posterior fusion & $5507(25.5 \%)$ \\
Anterior stabilization & $4655(21.5 \%)$ \\
Posterior stabilization & $5492(25.4 \%)$ \\
Surgical complications (intra- and postoperative up to discharge) $)^{* *}$ & \\
Yes & $2117(9.8 \%)$ \\
No & $19,429(89.8 \%)$ \\
General medical complications (intra- and postoperative up to discharge) $* * *$ & \\
Yes & $563(2.6 \%)$ \\
No & $20,877(96.5 \%)$ \\
Modified Mirza invasiveness index (mean \pm SD) & $3.9 \pm 5.0$ \\
\hline
\end{tabular}

$B M I$ body mass index; $A S A$ American society of anaesthesiologists score; and $S D$ standard deviation *Classified as shown in Table 1; anterior and posterior refer to the location in the spine, not the approach **Nerve root damage, spinal cord damage, dura lesion, vascular injury, fracture of vertebral structures, epidural hematoma, other hematoma, radiculopathy, CSF leak, motor dysfunction, sensory dysfunction, bowel/bladder dysfunction, wound infection, implant malposition, implant failure, wrong level, other

***Anaesthesiological, cardiovascular, pulmonary, thromboembolism, death, cardiovascular, pulmonary, cerebral, kidney/urinary, liver/GI, thromboembolism, other

Fig. 2 Distribution of mMII in study population. Note: less frequent $\mathrm{mMII}$ values $(<1 \%$ of the study population) were summed in "Other"

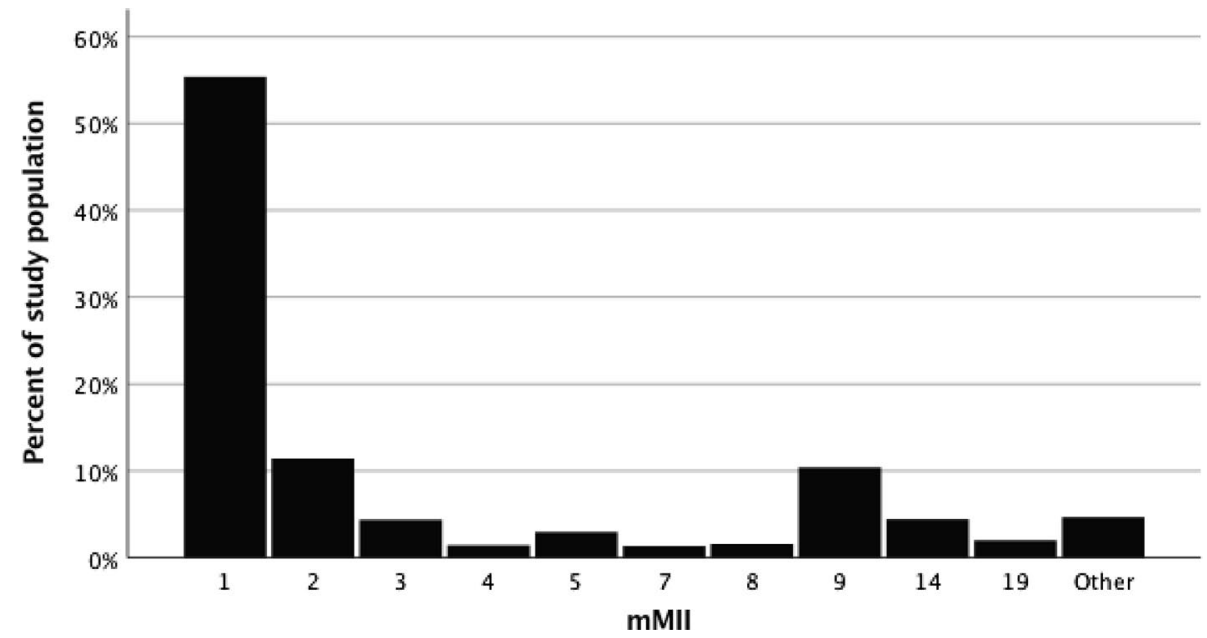

Table 3 Output from multiple regression in all patients, with blood loss (natural log transformed) as dependent variable

\begin{tabular}{|c|c|c|c|c|c|c|c|c|}
\hline \multirow[t]{2}{*}{ Model } & & \multicolumn{2}{|c|}{$\begin{array}{l}\text { Unstandardized } \\
\text { coefficients }\end{array}$} & \multirow{2}{*}{$\begin{array}{l}\text { Standardized } \\
\text { coefficients } \\
\text { Beta }\end{array}$} & \multirow[t]{2}{*}{$t$} & \multirow[t]{2}{*}{ Sig. } & \multicolumn{2}{|l|}{$95 \% \mathrm{CI}$ for $\mathrm{B}$} \\
\hline & & $B$ & Std. error & & & & Lower bound & Upper bound \\
\hline \multirow[t]{7}{*}{1} & (Constant) & 3.413 & 0.029 & & 116.132 & 0.000 & 3.356 & 3.471 \\
\hline & $\mathrm{mMII}$ & 0.128 & 0.001 & 0.611 & 113.194 & 0.000 & 0.126 & 0.130 \\
\hline & Age & 0.005 & 0.000 & 0.070 & 11.503 & 0.000 & 0.004 & 0.005 \\
\hline & Gender & 0.022 & 0.011 & 0.011 & 2.045 & 0.041 & 0.001 & 0.043 \\
\hline & BMI & 0.061 & 0.006 & 0.056 & 10.654 & 0.000 & 0.049 & 0.072 \\
\hline & ASA & 0.109 & 0.009 & 0.071 & 11.528 & 0.000 & 0.090 & 0.127 \\
\hline & $\begin{array}{l}\text { Number of previous } \\
\text { spine surgeries }\end{array}$ & 0.015 & 0.007 & 0.011 & 2.084 & 0.037 & 0.001 & 0.030 \\
\hline
\end{tabular}


Table 4 Output from multiple regression in all patients, with operative time as dependent variable

\begin{tabular}{|c|c|c|c|c|c|c|c|c|}
\hline \multirow[t]{2}{*}{ Model } & & \multicolumn{2}{|c|}{ Unstandardized coefficients } & \multirow{2}{*}{$\begin{array}{l}\text { Standardized } \\
\text { coefficients } \\
\text { Beta }\end{array}$} & \multirow[t]{2}{*}{$t$} & \multirow[t]{2}{*}{ Sig. } & \multicolumn{2}{|l|}{$95 \% \mathrm{CI}$ for $\mathrm{B}$} \\
\hline & & $B$ & Std. error & & & & Lower bound & Upper bound \\
\hline \multirow[t]{7}{*}{1} & (Constant) & 22.430 & 2.161 & & 10.378 & 0.000 & 18.193 & 26.666 \\
\hline & $\mathrm{mMII}$ & 10.364 & 0.083 & 0.648 & 124.810 & 0.000 & 10.202 & 10.527 \\
\hline & Age & -0.151 & 0.029 & -0.031 & -5.250 & 0.000 & -0.208 & -0.095 \\
\hline & Gender & -0.951 & 0.749 & -0.006 & -1.198 & 0.231 & -2.507 & 0.605 \\
\hline & BMI & -0.450 & 0.419 & -0.005 & -1.076 & 0.282 & -1.271 & 0.370 \\
\hline & ASA & 16.455 & 0.693 & 0.141 & 23.731 & 0.000 & 15.096 & 17.814 \\
\hline & $\begin{array}{l}\text { Number of previous } \\
\text { spine surgeries }\end{array}$ & 2.003 & 0.545 & 0.019 & 3.677 & 0.000 & 0.935 & 3.071 \\
\hline
\end{tabular}

Table 5 Logistic regression for general medical complications

\begin{tabular}{|c|c|c|c|c|c|c|c|c|}
\hline & \multirow[t]{2}{*}{$B$} & \multirow[t]{2}{*}{ Std. error } & \multirow[t]{2}{*}{ Wald } & \multirow[t]{2}{*}{$\mathrm{df}$} & \multirow[t]{2}{*}{ Sig. } & \multirow[t]{2}{*}{ OR } & \multicolumn{2}{|c|}{$95 \% \mathrm{CI}$ for OR } \\
\hline & & & & & & & Lower & Upper \\
\hline $\mathrm{mMII}$ & 0.045 & 0.007 & 45.896 & 1 & 0.000 & 1.046 & 1.032 & 1.060 \\
\hline Age & 0.027 & 0.004 & 58.950 & 1 & 0.000 & 1.028 & 1.021 & 1.035 \\
\hline Gender & -0.062 & 0.087 & 0.502 & 1 & 0.479 & 0.940 & 0.792 & 1.116 \\
\hline BMI & 0.024 & 0.045 & 0.299 & 1 & 0.584 & 1.025 & 0.939 & 1.118 \\
\hline ASA & 0.773 & 0.073 & 113.250 & 1 & 0.000 & 2.167 & 1.879 & 2.498 \\
\hline $\begin{array}{l}\text { Number of previous } \\
\text { spine surgeries }\end{array}$ & 0.069 & 0.048 & 2.106 & 1 & 0.147 & 1.072 & 0.976 & 1.177 \\
\hline Constant & -8.091 & 0.294 & 757.294 & 1 & 0.000 & 0.000 & & \\
\hline
\end{tabular}

\begin{tabular}{|c|c|c|c|c|c|c|c|c|}
\hline & \multirow[t]{2}{*}{ B } & \multirow[t]{2}{*}{ Std. error } & \multirow[t]{2}{*}{ Wald } & \multirow[t]{2}{*}{$\mathrm{df}$} & \multirow[t]{2}{*}{ Sig } & \multirow[t]{2}{*}{ OR } & \multicolumn{2}{|c|}{$95 \% \mathrm{CI}$ for OR } \\
\hline & & & & & & & Lower & Upper \\
\hline $\mathrm{mMII}$ & 0.002 & 0.004 & 0.238 & 1 & 0.626 & 1.002 & 0.994 & 1.011 \\
\hline Age & 0.011 & 0.002 & 42.658 & 1 & 0.000 & 1.011 & 1.008 & 1.015 \\
\hline Gender & -0.292 & 0.047 & 38.920 & 1 & 0.000 & 0.747 & 0.682 & 0.819 \\
\hline BMI & 0.075 & 0.024 & 9.755 & 1 & 0.002 & 1.078 & 1.028 & 1.130 \\
\hline ASA & 0.283 & 0.040 & 51.111 & 1 & 0.000 & 1.327 & 1.228 & 1.434 \\
\hline $\begin{array}{l}\text { Number of previous } \\
\text { spine surgeries }\end{array}$ & 0.218 & 0.026 & 70.226 & 1 & 0.000 & 1.243 & 1.182 & 1.308 \\
\hline Constant & -4.122 & 0.133 & 954.774 & 1 & 0.000 & 0.016 & & \\
\hline
\end{tabular}

Table 6 Logistic regression for surgical complications general medical but not surgical complications (Tables 5, 6 , respectively). The odds ratio for surgical complications associated with the mMII was 1.002 (95\% CI 0.994-1.011; $p=0.63$ ) and for general medical complications, 1.046 (95\% CI 1.032-1.060; $p<0.001)$. This means that with every additional index point, the odds of a general medical complication increase by $4.6 \%$. The mMII was also a significant predictor of any complication (of either a surgical or general medical nature, as shown in Table 7) with an odds ratio of 1.013 (95\% CI 1.005-1.021; $p=0.001)$.

\section{Discussion}

The present study showed that the mMII can easily be calculated from the information documented in the Spine Tango registry. The mMII showed a significant association with parameters that indirectly reflect the invasiveness of an operation such as blood loss and operative time. Furthermore, it was associated with perioperative complications. We therefore believe it is a valid measure of surgical invasiveness that can be applied for use in future registry studies. 
Table 7 Logistic regression for any complications (surgical and general medical combined)

\begin{tabular}{|c|c|c|c|c|c|c|c|c|}
\hline & \multirow[t]{2}{*}{$B$} & \multirow[t]{2}{*}{ Std. error } & \multirow[t]{2}{*}{ Wald } & \multirow[t]{2}{*}{ df } & \multirow[t]{2}{*}{ Sig. } & \multirow[t]{2}{*}{ OR } & \multicolumn{2}{|c|}{$95 \% \mathrm{CI}$ for OR } \\
\hline & & & & & & & Lower & Upper \\
\hline $\mathrm{mMII}$ & 0.013 & 0.004 & 10.777 & 1 & 0.001 & 1.013 & 1.005 & 1.021 \\
\hline Age & 0.014 & 0.002 & 71.327 & 1 & 0.000 & 1.014 & 1.011 & 1.017 \\
\hline Gender & -0.250 & 0.043 & 33.114 & 1 & 0.000 & 0.779 & 0.715 & 0.848 \\
\hline BMI & 0.059 & 0.022 & 6.846 & 1 & 0.009 & 1.060 & 1.015 & 1.108 \\
\hline ASA & 0.386 & 0.037 & 109.900 & 1 & 0.000 & 1.471 & 1.368 & 1.581 \\
\hline $\begin{array}{l}\text { Number of previous } \\
\text { spine surgeries }\end{array}$ & 0.189 & 0.025 & 58.465 & 1 & 0.000 & 1.208 & 1.151 & 1.268 \\
\hline Constant & -4.352 & 0.127 & 1179.786 & 1 & 0.000 & 0.013 & & \\
\hline
\end{tabular}

Our study showed an overall mean mMII of 3.9 (SD 5.0) with a range from 0 to 40. Mirza et al. [4] had two much smaller study groups with younger patients and a wider range of pathologies of the whole spine, including degeneration, trauma, neoplasm, infection and revision surgery. They reported a mean original Mirza invasiveness index of 10.5 (in an active surveillance group, $n=873$ ) and 5.4 (in a passive surveillance group, $n=850$ ), with a range from 0 to 48 . The difference in the two surveillance groups was explained by the fact that the high-volume surgeons in the active surveillance group performed more complex procedures in contrast to the low-volume surgeons in the passive surveillance group. In terms of the procedures performed and their respective invasiveness, our study group was closer to Mirza et al. [4] passive surveillance group.

Comparing the studies in regard to the prediction of blood loss, Mirza et al. [4] showed a $R^{2}$ for their model of 0.54 , while the $R^{2}$ in our study was 0.43 . This indicates that $43 \%$ of the variance in blood loss was accounted for by the variables included in our multivariate model. In a univariate model, Mirza et al. [4] reported a $R^{2}$ of 0.44 for the index alone, and in our study, a comparable value of 0.41 was found. An increase of 1 point in the index was associated with an additional blood loss of $12.8 \%$ (95\% CI, 12.6-13.0) in our study and $11.5 \%$ (95\% CI, 10.8-12.3\%) in the study of Mirza et al. [4]. In relation to the prediction of operative time, Mirza et al. [4] showed an $R^{2}$ of 0.53 , while ours was 0.47 ; in univariate regression, Mirza et al. [4] reported a $R^{2}$ of 0.52 for the index alone, which compared well with our $R^{2}$ of 0.45 . The beta coefficients in the two studies were very similar: an increase of 1 point in the mMII was associated with an increase of operative time of $10.4 \mathrm{~min}$ (95\% CI, 10.2-10.5) in our study versus 12.8 min (95\% CI, 11.8-13.7) in Mirza et al. [4] The lower $\mathrm{R}^{2}$ values in our study might be caused by a more heterogeneous study population because of the data originating from 53 different clinics and 17 different countries versus only 2 clinics in the original publication. However, the differences between the studies in $R^{2}$ for operative time and in the change of operative time per unit increase in $\mathrm{mMII}$ are rather small and of questionable clinical relevance.
Mirza et al. [4] did not evaluate the association between the invasiveness index and perioperative complications. Campbell et al. [14] recently showed that both the number of segments fused and a more invasive approach (combined antero-posterior vs. only anterior or only posterior approach) correlated with a higher rate of perioperative complications. Lee et al. [15] investigated the postoperative occurrence of medical complications after spine surgery. They used the original Mirza invasiveness index to account for the invasiveness of the procedure. Their study showed a strong dose response of the invasiveness index with a postoperative medical adverse event, and their reported odds ratio of 1.063 (95\% CI 1.045-1.082) [15] compared well with ours (1.046 $\{95 \%$ CI $1.032-1.060\})$. These odds ratios indicate that a unit increase in the mMII of one point increases the odds of a complication by $5-6 \%$. This is a medium effect size for a 1-point increase in the mMII, but with an increase of multiple points in the mMII, the effect size grows. However, complications are dependent on a multitude of factors, do not occur with every surgery and are hence much more difficult to predict than, for example, blood loss and operative time. Also, the reporting of complications might be subject to variability within the registry as "what constitutes a complication" leaves some room for interpretation.

Our study was performed retrospectively with a large sample of patient data from a registry. This resulted in a number of limitations. The data in the registry were collected in 17 countries and 53 clinics. Operative procedures and techniques can vary considerably from country to country and even from clinic to clinic. For example, a posterior lumbar stabilization can be performed freehand, guided by fluoroscopy or with image-guided navigation [16]. Because of the setup and the technical aspects, this might result in considerably different operating time and blood loss for the same number of segments stabilized. With regard to this fact, it is surprising that our results are so close to those published by Mirza et al. [4] who included all operations carried out in just two clinics affiliated with one university. The large number of clinics in our study comes with a large number of operating surgeons with different levels of training 
and experience. In a future study, one could investigate the difference in the treatment for a specific pathology regarding invasiveness between countries or clinics within the registry.

The Spine Tango Surgery form (version 2011) is very detailed, but not designed specifically to calculate the original Mirza invasiveness index. For example, one documents whether a decompression, fusion or stabilization was performed, whether it was anterior or posterior, and the total number of segments operated on for the whole surgery, but it is not specified what procedure was performed on how many segments. The indicated procedures were multiplied by the total number of segments operated on for calculation of the mMII, assuming that each procedure was done on each operated level. However, in reality, this was unlikely to be the case. Because of this, our calculated mMII probably overestimates the true invasiveness and may have introduced some nonlinearity, since the effect would be expected to be more marked for the multilevel surgeries. The result would be that the effective $\mathrm{R}^{2}$ for blood loss and operative time would have been higher than calculated, and so too would be the increase of operative time and blood loss per unit mMII. The realization of this shortcoming led to improvements in the Spine Tango surgery form in its recent iteration (version 2017). The form is now more detailed, and for every category of procedure (decompression, fusion, stabilization), the exact vertebral level(s) on which it was performed is recorded. However, it still leaves some uncertainty if more than one specific type of procedure within a given category is indicated (e.g. both "interbody stabilization with cage" and "pedicle screws" within the "stabilization rigid" category). To ensure reliable results when calculating the mMII in future studies, it would be advisable to encourage documentation of exactly which procedures were performed on each vertebral level. To simplify the calculation of the mMII in the present study, we assumed that the lumbar interbody fusions (PLIF, TLIF, XLIF) were always performed with anterior and posterior fusion, whereas in reality, this might not have been the case and some may have been done without posterior fusion.

The Spine Tango Surgery form accounts for blood loss in categories $(<100 \mathrm{ml}, 100-500 \mathrm{ml}, 500-1000 \mathrm{ml}$, $1000-2000 \mathrm{ml},>2000 \mathrm{ml}$ ). For the statistical analysis, the mean values of each category were used to allow the regression coefficients to be interpreted in real units of volume, e.g. $300 \mathrm{ml}$ for the category $100-500 \mathrm{ml}$. The same was done for operative time, which was also recorded as a range (e.g. 2-3 h) but converted to the mean of the range (i.e. $2.5 \mathrm{~h}$ ) for statistical analysis. It was assumed that the real values of blood loss and operative time are normally distributed within those categories. If they are not, and they are either negatively or positively skewed, then there will be a bias by taking the mean.
To the best of our knowledge, the original Mirza invasiveness index has not previously been validated in any external data sets. It is important to confirm a new model or index in an external data set to show that it performs well outside of the development set [17]. Our study indicates that a version of the index, adapted for use with Spine Tango registry data, is a valid measure of the invasiveness of common degenerative spine surgery procedures. The index should be of use in future registry and benchmarking studies to control for surgical complexity. It may also constitute a valuable predictor variable in the development of comprehensive predictor models for complications, length of stay, revisions and possibly even patient outcomes.

\section{Conclusion}

The mMII showed similar strength in predicting important perioperative parameters such as blood loss and operative time to that reported in the original publication of Mirza et al. in 2008 [4]. As our study showed that the mMII can be used for a broader spectrum of data collected internationally, we consider it valid and generalizable. In future studies, the more detailed information documented on the new Spine Tango Surgery form (2017) can be used to investigate whether the variance $\left(R^{2}\right)$ in blood loss and operative time explained by the mMII can be improved.

Acknowledgements We would like to thank Professor Oliver Distler, Head of Department of Rheumatology at the University Hospital Zurich, Switzerland, for his advice and assistance in planning the study, especially in regard to the statistical analysis. We are grateful to all clinics participating in the Spine Tango registry and contributing data to it. Data from the following clinics were used in this study (ordered alphabetically by country): St Andrew's Hospital, Adelaide, Australia; Royal Adelaide Hospital, Spinal Surgery, Adelaide, Australia; Universitatsklinik fur Orthopadie der Medizinischen Universitat Wien, Austria; Grand Hopital de Charleroi, Orthopedie, Charleroi, Belgium; Cliniques Universitaires Saint-Luc, Orthopedie, Bruxelles, Belgium; Clinique Saint-Pierre, Orthopedie, Ottignies, Belgium; Clinique Edith Cavell, Orthopedie, Bruxelles, Belgium; Hospital das Clinicas de Ribeirao Preto, Ribeirao Preto, Biomecanica Medicina e Reabilitacao do Aparelho Locomotor, Ribeirao Preto, Brazil; Universitatsklinik Koln, Klinik fur Orthopadie und Unfallchirurgie, Koln, Germany; Universitatsklinik Koln, Neurochirurgie, Koln, Germany; Krankenhaus der Barmherzigen Bruder, Wirbelsaulenzentrum, Trier, Germany; Klinikum Uckermark, Orthopadische Klinik, Schwedt, Germany; Klinikum Offenbach GmbH, Neurozentrum Neurochirurgische Klinik, Offenbach, Germany; Gemeinschaftspraxis fur Orthopadie und Neurochirurgie, Hof, Germany; P. D. Hinduja National Hospital, Spine unit department of orthopaedics, Mumbai, India; Jadria Private Hospital, Spine, Baghdad, Iraq; Sant'Andrea Hospital Sapienza University of Rome, Neurochirurgia, Rome, Italy3; Istituto Ortopedico Villa Salus, Neurochirurgia, Melilli, Italy; IRCCS Galeazzi Orthopedic Institut, Milano, Italy; Clinica Cellini, Chirurgia Vertebrale, Torino, Italy; Spitalul Clinic de Traumatologie si Ortopedie, Spine surgery department, Chisinau, Moldova; Wojewodzki Szpital Specjalistyczny nr 2, Neuorchirurgia, Jastrzębie-Zdroj, Poland; Uniwersytecki Szpital Kliniczny, Klinika Ortopedii i Traumatologii, 
Wroclaw, Poland; SCM Polanica, Neurosurgery, Polanica-Zdroj, Poland; Medical University of Silesia, Department of Neurosurgery and Neurotraumatology, Katowice, Poland; General Hospital Torun, Department of Neurosurgery, Torun, Poland; Hospital Sao Joao, Neurosurgery, Porto, Portugal; University Clinic Orthopedics, Orthopedic clinic, Ljubljana, Slovenia; Orthopaedic Hospital Valdoltra, Spine surgery and paediatric orthopaedics, Ankaran, Slovenia; Hospital Universitario Virgen de la Arrixaca, Departamento de Cirugia Ortopedica y Traumatologia, Murcia, Spain; Hospital Sant Pau, Cirugia Ortopedica y Traumatologia, Barcelona, Spain; Spital Sonnenhof, Orthopädie, Bern, Switzerland; Spital Schwyz, Orthopadische Klinik, Schwyz, Switzerland; Schulthess Klinik, Wirbelsaulenzentrum, Zurich, Switzerland; Salem Spital, Neurochirurgie, Bern, Switzerland; Kantonsspital St. Gallen, Klinik fur orthopadische Chirurgie und Traumatologie, St. Gallen, Switzerland; Inselspital, Neurosurgery, Bern, Switzerland; Hopital Cantonal Fribourg, Orthopedie, Fribourg, Switzerland; Hirslanden Klinik Birshof, Zentrum fur Wirbelsaulenmedizin, Munchenstein, Switzerland; Das Rückenzentrum, Wirbelsäulenmedizin, Thun, Switzerland; Clinique Generale de Fribourg, Neurochirurgie, Fribourg, Switzerland; CHUV, Colonne vertebrale, Lausanne, Switzerland; Bethesda Spital, Neurochirurgie, Basel, Switzerland; Gazi University Faculty of Medicine, Department of Neurosurgery, Ankara, Turkey; Salford Royal NHS Trust, Spinal Department, Salford, UK; Salford Royal NHS Foundation Trust, Department of Neurosurgery, Manchester, UK; Royal Derby Hospital, spinal unit, Derby, UK; Nuffield Orthopaedic center, spinal unit, Oxford, UK; The Walton Centre NHS Foundation Trust, Department of Neurosurgery, Liverpool, UK; Christiana Care Hospital, Department of Spine Surgery, Newark, Delaware, USA.

Funding Open access funding provided by University of Zurich. No funding was received.

\section{Compliance with ethical standards}

Conflict of interest We have no potential conflict of interest.

\section{Ethics approval KEK-ZH-2014-0418.}

Availability of data and material The datasets generated during and/or analysed during the current study are not publicly available because the datasets were given to us by EUROSPINE for this study only but are available from the corresponding author (respectively, from the Spine Tango Taskforce of EUROSPINE) on reasonable request.

Code availability (software application) Statistical analysis was carried out using SPSS version 25 (IBM Corp., USA, 2017).

Open Access This article is licensed under a Creative Commons Attribution 4.0 International License, which permits use, sharing, adaptation, distribution and reproduction in any medium or format, as long as you give appropriate credit to the original author(s) and the source, provide a link to the Creative Commons licence, and indicate if changes were made. The images or other third party material in this article are included in the article's Creative Commons licence, unless indicated otherwise in a credit line to the material. If material is not included in the article's Creative Commons licence and your intended use is not permitted by statutory regulation or exceeds the permitted use, you will need to obtain permission directly from the copyright holder. To view a copy of this licence, visit http://creativecommons.org/licenses/by/4.0/.

\section{References}

1. Mirza SK, Deyo RA, Heagerty PJ, Turner JA, Lee LA, Goodkin $R$ (2006) Towards standardized measurement of adverse events in spine surgery: conceptual model and pilot evaluation. BMC Musculoskelet Disord 20(7):53. https://doi.org/10.1186/1471-2474-7-53

2. Weinstein JN, Lurie JD, Olson PR, Bronner KK, Fisher ES (2006) United States' trends and regional variations in lumbar spine surgery: 1992-2003. Spine (Phila Pa 1976) 31(23):2707-14. https://doi. org/10.1097/01.brs.0000248132.15231.fe

3. Lurie JD, Tosteson TD, Tosteson AN, Zhao W, Morgan TS, Abdu WA, Herkowitz H, Weinstein JN (2014) Surgical versus nonoperative treatment for lumbar disc herniation: eight-year results for the spine patient outcomes research trial. Spine (Phila Pa 1976) 39(1):316. https://doi.org/10.1097/BRS.0000000000000088

4. Mirza SK, Deyo RA, Heagerty PJ, Konodi MA, Lee LA, Turner JA, Goodkin R (2008) Development of an index to characterize the "invasiveness" of spine surgery: validation by comparison to blood loss and operative time. Spine (Phila Pa 1976) 33(24):2651-61. https ://doi.org/10.1097/BRS.0b013e31818dad07

5. Cassinelli EH, Eubanks J, Vogt M, Furey C, Yoo J, Bohlman HH (2007) Risk factors for the development of perioperative complications in elderly patients undergoing lumbar decompression and arthrodesis for spinal stenosis: an analysis of 166 patients. Spine (Phila Pa 1976) 32(2):230-5. https://doi.org/10.1097/01.brs.00002 51918.19508.b3

6. Nuttall GA, Horlocker TT, Santrach PJ, Oliver WC Jr, Dekutoski MB, Bryant S (2000) Predictors of blood transfusions in spinal instrumentation and fusion surgery. Spine (Phila $\mathrm{Pa}$ 1976) 25(5):596-601. https://doi.org/10.1097/00007632-20000 3010-00010

7. Cho KJ, Suk SI, Park SR, Kim JH, Kim SS, Choi WK, Lee KY, Lee SR (2007) Complications in posterior fusion and instrumentation for degenerative lumbar scoliosis. Spine (Phila Pa 1976) 32(20):2232-7. https://doi.org/10.1097/BRS.0b013e31814b2d3c

8. Olsen MA, Nepple JJ, Riew KD, Lenke LG, Bridwell KH, Mayfield J, Fraser VJ (2008) Risk factors for surgical site infection following orthopaedic spinal operations. J Bone Joint Surg Am 90(1):62-69. https://doi.org/10.2106/JBJS.F.01515

9. Fritzell P, Hägg O, Nordwall A (2003) Complications in lumbar fusion surgery for chronic low back pain: comparison of three surgical techniques used in a prospective randomized study. A report from the Swedish Lumbar Spine Study Group. Eur Spine J 12(2):178-89. https://doi.org/10.1007/s00586-002-0493-8

10. Lønne G, Fritzell P, Hägg O, Nordvall D, Gerdhem P, Lagerbäck T, Andersen M, Eiskjaer S, Gehrchen M, Jacobs W, van Hooff ML, Solberg TK (2019) Lumbar spinal stenosis: comparison of surgical practice variation and clinical outcome in three national spine registries. Spine J 19(1):41-49. https://doi.org/10.1016/j.spine e.2018.05.028

11. Sigmundsson FG, Jönsson B, Strömqvist B (2017) Determinants of patient satisfaction after surgery for central spinal stenosis without concomitant spondylolisthesis: a register study of 5100 patients. Eur Spine J 26(2):473-480. https://doi.org/10.1007/s00586-016-4495-3

12. Cheng T, Gerdhem P (2018) Outcome of surgery for degenerative lumbar scoliosis: an observational study using the Swedish Spine register. Eur Spine J 27(3):622-629. https://doi.org/10.1007/s0058 6-017-5248-7

13. Eurospine Spine Tango (2019) https://www.eurospine.org/spine -tango.htm. Accessed 5 Aug 2019

14. Campbell PG, Yadla S, Malone J, Maltenfort MG, Harrop JS, Sharan AD, Ratliff JK (2011) Complications related to instrumentation in spine surgery: a prospective analysis. Neurosurg Focus 31(4):E10. https://doi.org/10.3171/2011.7.FOCUS1134 
15. Lee MJ, Cizik AM, Hamilton D, Chapman JR (2014) Predicting medical complications after spine surgery: a validated model using a prospective surgical registry. Spine J 14(2):291-9. https://doi. org/10.1016/j.spinee.2013.10.043

16. Rahmathulla G, Nottmeier EW, Pirris SM, Deen HG, Pichelmann MA (2014) Intraoperative image-guided spinal navigation: technical pitfalls and their avoidance. Neurosurg Focus 36(3):E3. https://doi. org/10.3171/2014.1.FOCUS13516
17. Moons KG, Kengne AP, Grobbee DE, Royston P, Vergouwe Y, Altman DG, Woodward M (2012) Risk prediction models: II. External validation, model updating, and impact assessment. Heart 98(9):691-8. https://doi.org/10.1136/heartjnl-2011-301247

Publisher's Note Springer Nature remains neutral with regard to jurisdictional claims in published maps and institutional affiliations. 